\title{
Cartografías de la ciudad. Representación y estilización lingüística en mapas mentales de Buenos Aires
}

\author{
Melanie Würth \\ Universität Bern, Suiza / SNF
}

\begin{abstract}
Resumen
Desde un enfoque constructivista del espacio urbano como producto social, en el presente artículo presentamos algunos aspectos teóricos y metodológicos para el análisis de las representaciones geosociales y la identidad urbana para luego investigar a partir de una selección de mapas mentales la imagen espacial que los hablantes expresan a través de las variedades lingüísticas que distinguen, estilizan y ubican en su cartografía mental de la ciudad. Se trata de un primer acercamiento a un corpus recopilado en 2013, que permite observar, por un lado, que la percepción del espacio urbano está basada en la fuerte identificación de los porteños con los barrios de la ciudad y, por otro lado, que existe en el imaginario colectivo una dicotomía norte-sur estilizada que se refleja tanto en lo social, como en lo espacial y lo lingüístico.
\end{abstract}

Palabras clave: español de Buenos Aires, dialectología perceptiva, mapas mentales, representación geosocial.

Para correspondencia, dirigirse a: Melanie Würth (melanie.wuerth@rom.unibe.ch), Institüt für spanische Sprache und Literaturen, Universität Bern, Länggassstrasse 49, 3012 Bern, Suiza. 
Cartographies of the City: Representation and linguistic STYLIZATION IN MENTAL MAPS OF BuENOS Aires

\begin{abstract}
In this article we present some theoretical and methodological reflections for the analysis of geosocial representations and urban identity from a constructivist approach, understanding the urban space as a social product. Based on a selection of mental maps compiled in Buenos Aires in 2013, we will investigate the spatial image that the inhabitants of this city express through linguistic varieties they single out, stylize and situate in their mental cartography. This analysis shows, first, that the perception of the urban space of the porteños is based on strong identification with their neighbourhood, and second, that in the collective imaginary there is a distinctive dichotomy between north and south that is reflected in the social, the spatial as well as in the linguistic.
\end{abstract}

Keywords: Spanish in Buenos Aires, perceptual dialectology, mental maps, socio-spatial representation.

Recibido: 12/05/14 Aceptado: 18/08/14 
La configuración de la ciudad no obedece tanto a un plan arquitectónico como a una manera particular de ver, sentir y pensar la vida: es la encarnación, tangible y material, de una visión de mundo. Antes de ser piedra, cemento o ladrillo, las ciudades son una imagen.

Octavio Paz (1990)

\section{INTRODUCCIÓN ${ }^{1}$}

Cualquier habitante de cualquier espacio urbano realiza asociaciones con alguna parte de su ciudad, y sus imágenes están compenetradas por memorias y significados (Lynch 1960: 1). Si uno piensa en la ciudad en la que vive, automáticamente surgirán en su mente impresiones, lugares, calles, plazas, edificios tal vez, o quizás hasta una especie de plano, de cartografía mental a base de la cual nos orientamos en el espacio. Con algunos de estos lugares tal vez asociamos vivencias o momentos concretos, de modo que ahora les atribuimos un valor simbólico, y de otros, en cambio, tenemos conocimientos mucho más vagos. Algunos los valoramos positivamente, tal vez nos gustaría vivir allí, y otros nos causan más recelo o rechazo. Y muy posiblemente nos identifiquemos con alguna zona dentro de este espacio, tal vez nuestro barrio de residencia, por diferentes motivos: quizás porque nos identificamos con la gente que vive en el mismo lugar, quizás nos gusta la arquitectura, la oferta gastronómica o cultural, o las comodidades que nos ofrece. Y si nos sentimos pertenecientes a un lugar, muy probablemente también tenemos una imagen de las personas que viven en otras zonas, de su estatus social, de su estilo de vida, tal vez de su orientación política y, por qué no, de su forma de hablar.

\footnotetext{
Este artículo se ha escrito en el marco del proyecto de investigación "La ciudad como constructo geosocial. Percepción, representación y actitud frente a las variedades lingüísticas de la Región Metropolitana de Buenos Aires", patrocinado por el Fondo Nacional Suizo. Proyecto nro. 100012_140507 (Cf. http://www.espanol.unibe.ch/content/proyectos_de_investigacin/ index_spa.html)
} 


\section{LA CIUDAD - DIVERSIDAD Y CONEXIÓN DE MUNDOS SOCIALES}

Visto desde varias perspectivas, el espacio urbano presenta una dinámica social extremadamente compleja. La ciudad se caracteriza, principalmente, por una gran cantidad de personas que viven en un territorio (relativamente) limitado, por la densidad en la que conviven dentro de este espacio, y la heterogeneidad de individuos y de grupos que se encuentran en la urbe (Mac Giolla Chríost 2007: 15). "Cities have in common the fact that they make people more physically accessible to one another, in more or less shared, limited space" (Hannerz 1980: 243). Cabe subrayar aquí dos aspectos inherentes a la vida urbana que están relacionados entre sí y que son fundamentales para nuestro trabajo: la diversidad y la conexión (Mac Giolla Chríost 2007: 14ss.). En tanto espacio de proximidad, de copresencia y de encuentro, la ciudad reúne una multiplicidad de mundos sociales e identidades urbanas distintos y dinámicos (Mac Giolla Chríost 2007: 17). Sin embargo, es recién en el encuentro, en la interacción con el "otro", con el stranger (Mac Giolla Chríost 2007: 15) donde se muestra la diversidad, donde se negocian jerarquías sociales y apropiaciones espaciales. Esta presencia del "otro" es clave para la formación de identidades urbanas, para la percepción tanto de uno mismo como de otros grupos sociales o de variedades lingüísticas, así como para el desarrollo del mapa mental, como veremos más adelante.

\subsection{EL ESPACIO URBANO COMO PRODUCTO SOCIAL}

Partimos para el presente trabajo de un enfoque constructivista, es decir, se considera el espacio como producto social, construido y moldeado por quienes lo habitan, por las imágenes colectivas, sociohistórica y culturalmente motivadas (Johnstone 2004: 69; Bürki 2014: 1) que desarrollan de su entorno, y sus prácticas sociales. En este sentido, Caravedo sugiere comprender el espacio desde una dimensión conceptual como espacio mental, refiriéndose al hecho de que "los espacios, siendo realidades materiales, no tienen el mismo valor ni las mismas características para todos los seres humanos" (2012: 7). Para el ámbito de la lengua, esto significa que

los hablantes elaboran -sobre la base de creencias transmitidas de generación en generación a las que se añaden las de la propia experiencia vital-ideas, no siempre justificadas ni razonadas sobre el espacio ajeno, 
en relación con las cuales, reconocen y evalúan modalidades o dialectos diversos de los propios. Gran parte de las valoraciones lingüísticas se basan en esas conceptualizaciones que son, en verdad, solo creencias o suposiciones que no necesariamente tienen correspondencia exacta con una realidad fáctica, de tal modo que pueden llegar a ser falsas, imprecisas o arbitrarias (Caravedo 2012: 7s.).

Es decir, el espacio deja de verse como mero territorio de asentamiento humano (en el sentido de container ${ }^{2}$ para las prácticas sociales), sino que adquiere un valor simbólico, producto de una construcción mental en la que los hablantes tienen una participación activa ${ }^{3}$ (Caravedo 2012: 8). El hecho de que se le atribuya más importancia a la perspectiva subjetiva de los hablantes y a la componente mental del espacio no significa, sin embargo, que se desconozca su aspecto físico. Al contrario, en la construcción del espacio, la dimensión física entra en una relación dialéctica con la dimensión subjetiva ${ }^{4}$. Por eso, Caravedo (2006: 8-10) propone una concepción del espacio urbano constituido por tres niveles: el material, el social y el simbólico. El primer nivel corresponde a la materialidad del espacio, a la ciudad como espacio geopolítico que tiene determinadas características físico-geográficas y arquitectónico-culturales, "ligadas a una historia y a una tradición urbanística y cultural que se continúa y evoluciona a través del tiempo" y está dividido en distritos administrativos (Caravedo 2012: 8). En segundo lugar, el espacio urbano responde a un orden social: "las ciudades son quienes habitan en ellas" (Caravedo 2012: 9). Como veremos en el siguiente capítulo, la ciudad reúne individuos de diversos orígenes que se encuentran en redes sociales más o menos densas, que se identifican con diferentes grupos sociales y crean, de esta manera, estilos de vida o identidades distintas que se manifiestan en las prácticas de interacción de las que participan día a día dentro del espacio urbano (Bürki 2014: 4). Y por último, en su dimensión simbólica, la cual solapa todo lo material, las ciudades o los elementos del espacio físico se cargan de significados que sus

\footnotetext{
2 Véase Günzel 2010: 192ss.

3 La importancia de la perspectiva subjetiva del hablante en el espacio empezó a tratarse sistemáticamente en la sociolingüística con los trabajos de Preston (1999), Johnstone (2004), Eckert (2000), Fought (2004), Milroy (2004) y Auer (2007).

$4 \quad$ Véase, al respecto, La production de l'espace, del sociólogo francés Henri Lefebvre (1974), quien en su obra precursora para la geografía moderna y la concepción actual del espacio presenta un modelo tripartito: el espacio percibido, el espacio concebido y el espacio vivido.
} 
habitantes les asignan y que van construyendo a través de sus experiencias personales y memorias compartidas.

\subsection{LA IDENTIDAD SOCIAL URBANA}

Ahora bien, si, como hemos apuntado anteriormente, el espacio ha de ser considerado como una construcción social, "la distinción entre medio físico y medio social tiende a desaparecer y el entorno pasa a ser no solo el escenario de la interacción sino [...] un elemento más de la interacción" (Valera y Pol 1994: 4). Es decir, la función del entorno no se reduce a la de un marco físico para la práctica social, sino que se establece una relación de "diálogo simbólico" entre individuos y grupos con el espacio, en el que éste les transmite a sus habitantes determinados significados sociales que ellos interpretan y reelaboran" (Valera y Pol 1994: 4). Sobre esta base, se construye una identidad social que puede derivarse de un sentimiento de pertenencia o afiliación a un entorno o un lugar concreto, junto con el significado valorativo y emocional asociado a esta pertenencia (Valera y Pol 1994: 3 y 5). Las categorías que pueden reconocerse como significativas son, con distinto nivel de abstracción, la ciudad, la zona, el barrio, e incluso pueden ser espacios más reducidos, como por ejemplo manzanas concretas dentro de un barrio (Valera 1997: 18). Según Valera y Pol, la identidad social urbana, que se encuentra en la línea del concepto de place-identity desarrollado por Proshansky (1978), consiste en un "conjunto de cogniciones referentes a lugares o espacios" que el individuo habita y en función de los cuales desarrolla "vínculos emocionales y de pertenencia a determinados entornos", frente a otros de los que no se siente parte (Valera y Pol 1994: 6). Este depósito cognitivo vinculado al espacio también se puede entender en el sentido de la representación social (y socioespacial), concepto desarrollado inicialmente en el ámbito de la psicología social por Moscovici (1984) y Jodelet $(1982 ; 1989)$ y que en las últimas décadas ha tenido un desarrollo conceptual y metodológico importante en varias disciplinas (de Alba 2011: 7). En términos muy generales, según Jodelet (1989: 5), la representación social es "una manera de interpretar y de pensar nuestra realidad cotidiana". Concierne a un conocimiento que se constituye a partir de nuestras experiencias individuales, pero también de las informaciones, conocimientos y modelos de pensamiento que recibimos y transmitimos de generación en generación a través de la tradición, la educación y la comunicación social (Jodelet 1989: 5). Este bagaje cultural y social, a su vez, mediatiza nuestro comportamiento, nuestras relaciones sociales y nuestra percepción del entorno que nos rodea (de Alba 2004: 134; 2011: 6). En relación con 
el espacio urbano, las representaciones sociales son, en primer lugar, el producto mental de procesos sociales, económicos, políticos, culturales e históricos de la ciudad que se transforma en el tiempo, como también de memorias asociadas a determinados lugares o pertenencias socio-territoriales dentro de la urbe. Por otra parte, como hemos visto, a través de los sistemas de representación también se produce significado - determinados elementos (verbales o no verbales) funcionan como símbolos para determinados grupos sociales o zonas urbanas y se perciben, interpretan y evalúan como tales (Hall 1997: 16).

\subsection{Percepción Y estilizACIÓN}

Según Valera (1997: 20), para que un espacio simbólico pueda funcionar como rasgo constituyente de la identidad urbana, es necesario que sea percibido por los individuos del grupo como prototípico, es decir, "paradigmático o representativo de la categoría urbana sobre la cual se fundamenta la identidad social urbana del grupo". De esta manera, la dimensión espacial se agrega a la serie de elementos estéticos y lingüísticos que se perciben como indexicales o salientes para un determinado grupo social. La percepción es un proceso cognitivo que, según lo destaca Caravedo (2013: 8) (desde un punto de vista lingüístico) se define por su carácter selectivo, orientado y diverso. En primer lugar, debido a la incapacidad de los seres humanos de aprehender todos los detalles de su entorno o de una lengua, no todos los fenómenos se perciben de la misma manera:

No todos los rasgos de una lengua son objeto de percepción, pues la atención del hablante solo se puede concentrar en algunos puntos, precisamente aquellos en que se asocia una forma con un espacio mental negativo o con un grupo minusvalorado en relación con una ubicación en el espacio urbano (2012: 13).

Esto significa que la percepción se concentra solo en ciertos aspectos -que de este modo se hacen salientes- mientras que muchos otros son desatendidos (Caravedo 2013: 8). No obstante, la selección de ciertos rasgos y el desapercibimiento de otros no parecen estar regidos por las propiedades de los fenómenos mismos, sino que la percepción que un individuo tiene de su entorno está orientada solo hacia algunos aspectos de este mismo a través de agentes externos y sociales (la familia, la escuela, la comunidad y, según nuestra opinión, también los medios de comunicación) (Caravedo 2013: 8). Y por último, entrando ya en el nivel de la valoración -que presupone la percepción, pero por el otro lado, la percepción no necesariamente tiene 
que implicar una valoración- un mismo fenómeno de la misma lengua no siempre es percibido de igual manera por los hablantes de la comunidad y, además, puede ser valorado con una actitud muy diferente (Caravedo 2013: 9). Estas valoraciones positivas o negativas de elementos de una lengua, de un grupo social o de un espacio remontan, otra vez, a la representación social que se va formando a lo largo de la vida de un individuo y que actúa como filtro para la percepción que tiene de su entorno.

Ahora bien, si algunos de estos rasgos percibidos como emblemáticos de un grupo social o un espacio se usan de forma metonímica para referirse a él o para estilizarlo, se crean estereotipos socioespaciales y lingüísticos, basados en un conocimiento cultural y social compartido (Pümpel-Mader 2010: 35), que se refieren de forma muy generalizada a todo un grupo social vinculado con una cierta zona o un determinado barrio (Auer 2007: 6).

En lo que sigue nos adentraremos pues en el mapa mental como expresión de la representación social y analizaremos, finalmente, cómo salen a la luz las categorías socioespaciales y los estereotipos lingüísticos en estas imágenes de la ciudad (en nuestro caso, Buenos Aires).

\section{CARTOGRAFÍAS URBANAS - EL MAPA MENTAL COMO REPRESENTACIÓN SOCIAL}

El interés científico por cómo personas crean imágenes del espacio que habitan no es un fenómeno reciente (de Alba 2011: 2). Desde principios del siglo $\mathrm{xx}$, la orientación espacial del ser humano se convierte en una cuestión cada vez más importante y objeto de estudio para la geografía, la

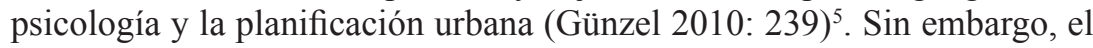
estudio experimental de mapas mentales no surge antes de la mitad del siglo xx, en el campo de la psicología cognitiva (de Alba 2011:2). Edward Tolman (1948) se sirve del término cognitive map para describir el comportamiento sistemático de ratas en su entorno y está convencido de que este purposive behaviorism funcionaría de igual manera para el ser humano (Günzel 2010: 240s.). Después de los experimentos de Tolman, el estudio de la orientación espacial se retoma en los años cincuenta, con un enfoque más cognitivo:

\footnotetext{
5 Véase, por ejemplo, Orientation of maps de Frederic P. Gulliver (1908) u "On
} Fundamental Methods of Orientation and Imaginary Maps" de Charles Trowbridge (1913). 
David Lynch (1960) es el primero en usar el concepto de mapas mentales y la técnica de dibujar esquemas sobre un papel para analizar las representaciones que habitantes de una ciudad se forman de su espacio (de Alba 2011: 2). Con vistas a cuestiones urbanísticas, el autor se dedica al aspecto visual de ciudades, al significado de su paisaje y sus transformaciones (Riaño 2013: 27). La imagen dibujada refleja la relación de los habitantes con su espacio de vivencia, de trabajo y de ocio.

Moving elements in a city, and in particular the people and their activities, are as important as the stationary physical parts. We are not simply observers of this spectacle, but are ourselves a part of it, on the stage with the other participants. Most often, our perception of the city is not sustained, but rather partial, fragmentary, mixed with other concerns. Nearly every sense is in operation, and the image is the composite of them all (Lynch 1960: 2).

Su trabajo The Image of the City puede considerarse como estudio precursor y muy inspirador para el desarrollo teórico y metodológico en materia de estudios urbanos, y por su metodología innovadora y las ideas para analizar las representaciones del espacio urbano ha motivado una serie de investigaciones acerca de la ciudad en varias disciplinas, como, por ejemplo, el urbanismo, la arquitectura, la psicología, o la geografía (Jackson y Kitchin 1998; de Alba 2009: 12 y 2011: 2). Con el desarrollo de las ciencias cognitivas, el concepto de "mapa cognitivo" empieza a tratarse sistemáticamente para investigar cualquier tipo de información vinculada espacialmente (Downs y Stea 1982; 1985). La representación mental que remite al espacio se convierte en objeto de estudio (Günzel 2010: 242):

Cognitive mapping is a process composed of a series of psychological transformations by which an individual acquires, stores, recalls, and decodes information about the relative locations and attributes of the phenomena in his everyday spatial environment (Downs y Stea 1973: 9).

Milgram y Jodelet (1976) realizaron un estudio sobre las representaciones de París en el contexto de esta línea de investigación, tratando los mapas mentales como representaciones sociales y considerando, además, los significados sociales, culturales e históricos de la ciudad como factores que entran en juego en la formación de imágenes sobre ella (de Alba 2011: 3). Ya en el trabajo de Peter Gould (1972) sobre preferencias en cuanto a zonas residenciales en Estados Unidos, que evalúa imaginarios colectivos sobre regiones y ciudades, destaca el factor cualitativo de mapas mentales (Günzel 2010: 245). En consecuencia, la investigación mediante mapas mentales se 
ocupa cada vez más de los significados, sentimientos y valores que influyen en la percepción de espacios y condicionan la práctica espacial, como lo repite el geógrafo Rob Kitchin más tarde, en los años noventa: "Cognitive maps [...] are not just a set of spatial mental structures denoting relative position, they contain attributive values and meanings" (Kitchin 1994: 2). Esta idea del aspecto evaluador y simbólico es clave para nuestro trabajo.

Uno de los pioneros en emplear mapas mentales en la lingüística, concretamente para el estudio de la percepción de la variación dialectal fue Preston (1989; Long y Preston 1999-2002) quien, interesado en los conocimientos de personas no expertas sobre las variedades lingüísticas, desarrolló la disciplina de la Dialectología Perceptiva (Perceptual Dialectology, a veces también llamada Folk Linguistics), un cambio de enfoque de la producción a la percepción de fenómenos lingüísticos, y sentó así las bases para una larga serie de trabajos vinculados con otras disciplinas, como por ejemplo, la sociolingüística, la etnografía, la psicología, la antropología social y la geografía ${ }^{6}$. Partiendo de la pregunta de cómo perciben y valoran los hablantes de un determinado espacio las variedades lingüísticas propias y ajenas ${ }^{7}$, Preston trabaja mayormente en una macroescala sobre la percepción de las diferencias dialectales en América del Norte.

En el presente trabajo vamos a centrarnos en un espacio más limitado, aunque para un área urbana sí ocupa un terreno amplio y, como gran metrópolis, representa un espacio sumamente complejo desde una perspectiva tanto socioespacial como lingüística.

\section{LA CIUDAD DE BUENOS AIRES}

La ciudad de Buenos Aires se extiende sobre una superficie algo superior a los $200 \mathrm{~km}^{2}$ y cuenta actualmente con cerca de tres millones de habitantes (y aproximadamente trece millones en su aglomerado urbano, el Gran

\footnotetext{
6 Véase los trabajos reunidos en los dos volúmenes de Handbook of Perceptual Dialectology (Long y Preston 1999-2002).

7 Aunque hay que mencionar algunos lingüistas (p. ej. Krefeld y Pustka 2011) que le critican el no haber trabajado con estímulos de lengua y por tanto reducen el carácter meramente perceptivo de su trabajo.
} 
Buenos Aires) que residen en 48 barrios $^{8}$. Momento clave para el incremento poblacional, la urbanización y la estructura demográfica de la ciudad como se presenta hoy en día fue, como es bien sabido, la inmigración masiva desde Europa a finales del siglo xIX y principios del siglo xx. En el transcurso del crecimiento explosivo de la población, Buenos Aires expande su superficie y consolida un anillo de barrios suburbanos que se convierten en una parte social, arquitectónica y espacial integrada e integrativa de la ciudad (Luczak 2010: 40). La estructura reticulada de la ciudad latinoamericana funciona en este proceso como base de planificación urbana y facilita una expansión igualada e integrada del espacio (Gorelik 1993: 110). A esta época se remonta la formación de los barrios porteños como elemento de una fuerte identificación socioespacial para los habitantes de la ciudad:

A porteño's sense of place and urban identity is related immediately to his or her barrio. [...] Urban growth during the nineteenth and twentieth centuries melded the various neighbourhoods together into a huge urban expanse, one part seemingly indistinguishable from another. However, the barrios and their edges and boundaries remain, celebrated in poetry and tango, and reinforced by fierce rivalries between neighbourhood sports teams, political affiliations, ethnic divisions, and traditional attitudes. Indeed, the essence of the barrio has remained relatively unchanged for over 100 years (Keeling 1996: 211).

Este sentido de pertenencia a un lugar geográfico -que a veces hasta se expresa en una "mitificación" de determinados barrios-persiste, como dice Keeling (1996), hasta hoy en día y sobrepasa aun profundas transformaciones urbanas. Se trata pues de un rasgo muy anclado en la representación social y el imaginario colectivo de los habitantes de Buenos Aires - un aspecto que ha de tenerse en cuenta para el análisis de los mapas mentales.

A partir de los años setenta y, de manera más intensa, en la década de los noventa, las medidas estructurales del Estado - entre ellas la implementación poco controlada de un modelo económico neoliberal y la privatización de la planificación urbana- hicieron de la ciudad un espacio economizado, privatizado y geográfica y socioculturalmente segregado (Luczak 2010: 53). Bajo la influencia cada vez más visible de los procesos de globalización, que entrelazan determinados sectores de la ciudad, particularmente en zonas de mayor estatus social, con estructuras económicas, políticas y culturales

8 Cifras basadas en el censo de 2010: http://www.buenosaires.gob.ar/laciudad/ciudad $[24 / 4 / 14]$ 
uniformadoras que traspasan las fronteras nacionales, mientras gran parte de la población urbana queda excluida de estos procesos, la fragmentación y las divergencias socioespaciales dentro de la ciudad se acentúan aún más (Torres 2001: 7; Ciccolella 1999, sin paginación). Esta reestructuración del espacio urbano de Buenos Aires lleva a que el sentimiento de pertenencia y la identificación con un determinado barrio, una determinada zona urbana o un cierto grupo social se vuelvan a reforzar, lo cual se manifiesta en un conjunto de estilos -rasgos estéticos, preferencias de consumo, expresiones culturales, como también variantes lingüísticas, como demuestra la mención de este hablante de Barrio Norte:

Cuando vos escuchás hablar a alguien ya sabés más o menos de qué barrio es. Por la forma de vestirse, por la forma de hablar, por la actitud, por el corte de pelo, por la ropa, por todo?.

En un sistema de distinción social y espacial (Irvine 2001: 22), estos elementos sirven para crear un contraste entre un "nosotros" y un "ellos" y son interpretados socialmente. Asimismo, muchos de ellos se usan de manera generalizada para crear estereotipos, como hemos visto. En Buenos Aires podemos observar una dicotomía de categorías socio-espaciales: el cheto y el negro.

\subsection{LOS CHETOS DEL NORTE}

Cheto es un vocablo que viene de la palabra lunfarda shusheta, derivada del genovés sciuscetta ('delator, confidente'), con el significado de 'joven vestido a la moda, elegante, pisaverde, refinado' 10 , o también 'petimetre, persona que cuida excesivamente de su compostura' ${ }^{11}$. De ahí en español se hizo concheto, con el significado de 'una persona que es frívola y tiene mucho dinero o se comporta como si lo tuviera' (DIEA, s.v. concheto), y por aféresis se dio cheto, con un significado parecido. Se trata de un estereotipo social y claramente geográfico respecto de las personas que

\footnotetext{
9 Esta cita procede de un trabajo de campo anterior, en 2008, en el cual también se realizaron entrevistas y se les hizo a los informantes preguntas sobre las diferencias sociales y culturales dentro de la ciudad. Véase Würth, Melanie (2009): La Ciudad como área lingüística. Variación y actitudes en el habla de la Región Metropolitana de Buenos Aires. Tesis de licenciatura sin publicar.

$10 \mathrm{http}: / /$ www.todotango.com/spanish/biblioteca/lexicon/s.asp

$11 \mathrm{http} / / / \mathrm{www}$. clubdetango.com.ar/lunfardeando/shusheta.htm
} 
viven en los barrios norteños de la ciudad. Este arraigo geográfico es tan fuerte y tan convencionalizado que incluso el Diccionario integral del español de la Argentina (DIEA) del año 2010 da como ejemplo para el uso de concheto como sustantivo: Es un concheto de barrio norte (DIEA, s.v. concheto, la negrita es nuestra). Si bien no corresponde a una denominación administrativa oficial, barrio norte es una expresión totalmente común y frecuente para referirse a la zona norteña de estatus socioeconómico alto de la ciudad, que incluye el barrio de Recoleta y una parte de Retiro, aunque existen diferentes puntos de vista en cuanto a las calles y avenidas que marcan sus límites ${ }^{12}$. Pero en el imaginario colectivo, el "norte" de la ciudad, que en términos propiamente geográficos sería más bien un "noreste", una franja que comprende los barrios de Belgrano, Palermo, Recoleta y una pequeña parte de Retiro, y la denominación popular de "barrio norte" está estrechamente relacionada con el estereotipo del cheto.

Además de la ubicación geográfica, los rasgos estereotipados del cheto son de naturaleza tanto no verbales como verbales ${ }^{13}$. En el plano extralingüístico, por ejemplo, se lo caracteriza con un aspecto físico más "blanco" y "rubio", determinadas preferencias estéticas (p. ej. marcas de ropa) y musicales (música internacional, electrónica), tipos de deportes (p. ej. el rugby) o ciertas prácticas de tiempo libre. Al mismo tiempo, se le atribuye claramente una determinada forma de hablar: en el nivel léxico, se dice que los chetos usan más anglicismos, entre ellos, por ejemplo, man, sorry, fashion, please, que prefieren ciertas palabras "más cultas" a otras, por ejemplo colorado en vez de rojo o traje de baño en vez de malla, y que presentan mayor frecuencia de muletillas como tipo que, viste, como que, nada. En el plano fonético son dos los rasgos sobresalientes que se le atribuye al cheto: en primer lugar, la realización sonora de la palatal rehilada, o sea, $[\square]$ o [ $\square$ ], a diferencia de $[\square]$, que hoy en día es la variante más frecuente en el español de Buenos Aires ${ }^{14}$, y, en segundo lugar, una forma "más nasal"

12 Véase, por ejemplo, http://www.buenos-aires-argentina.info/barrio-norte.html o http:// www.barrio-norte.com/mapa.html

13 Véase, por ejemplo, la página http://www.frikipedia.es/friki/Cheto_(tribu_urbana) [30/3/14], un ejemplo ilustrativo de la construcción popular del estereotipo del cheto. También destaca el uso de los estereotipos en los medios de comunicación, particularmente en los programas cómicos y las publicidades, de las que se podría mencionar, por ejemplo, la de las Papas Lay's: http://www.youtube.com/watch? v=itFB1Ulviu4 y http://www.youtube.com/ watch? $=$ C2RL0SFwG8 [5/4/14]

14 Existen varios trabajos acerca de este rasgo característico del español porteño. Para su proceso de ensordecimiento, consúltese Donni de Mirande (2000), Chang (2008) o Würth (2013). 
de hablar, que se caracteriza de manera extensiva con la metáfora "como si tuviera una papa en la boca", expresión que para los hablantes porteños se ha convertido en lugar común para referirse a "los chetos".

\subsection{LOS NEGROS DEL SUR}

Por el otro lado, el término negro -hoy en día- representa una especie de contrapunto al cheto. La denominación negro se remonta a la época del desarrollo industrial durante el peronismo de los años cuarenta, cuando las personas de ascendencia indígena y de clase social baja que, con el fuerte incremento de la migración interna desde otras provincias se trasladaban a la ciudad de Buenos Aires pasaban a ser denominadas cabecitas negras, por alusión a su aspecto físico (Frigerio 2006: 86; James 2012: 6). Esta construcción cultural claramente desdeñosa (James 2012: 6) fue el resultado de un momento decisivo para la estructura sociodemográfica de Buenos Aires: con la aparición de los obreros de tez morena se veía amenazada la "blanquedad porteña" y "surge una nueva categoría que se inserta dentro de los esquemas cognitivos referentes a las clasificaciones raciales" (Frigerio 2006: 86). Frigerio insiste en la connotación racial del término cabecita negra "para entender su popularidad y su efectividad como arma estigmatizante" (2006: 87). Aunque en la medida en que durante la segunda mitad de la década del 1950 los "cabecitas" se veían confinados espacialmente en las villas miserias, la denominación cabecita negra pasó a ser reemplazada, lentamente, por el mote villero (Frigerio 2006: 87), el término negro permanece aún varias décadas después. Actualmente se usan los vocablos negro, negro cabeza o simplemente cabeza para referirse a cualquier 'persona de extracción social humilde, especialmente la que es tosca y tiene poca cultura' (DIEA, s.v. cabecita negra). Según Frigerio, negro parece ser "el término más vigente, que engloba y a la vez trasciende a sus precedentes cabecita negra y villero" (2006: 87). El uso de la categorización de villero para las personas que vivían en las villas miserias, es decir, en los asentamientos precarios de Buenos Aires, hoy en día tampoco ya no es exclusivo para este contexto, sino que se extendió, de manera que sobre todo en un sentido despectivo, villero puede referirse también a cualquier persona de los estratos sociales bajos. Funciona, por lo tanto, como sinónimo o complemento de negro. Así, se escucha negro y villero para estereotipar a un mismo grupo, e incluso la combinación de negro villero. Lo que sí se conserva, sin embargo, es su arraigo geográfico. Al ser las zonas del sur y del oeste los destinos de mayor migración desde el interior del país, en el imaginario colectivo se ubican los estereotipos del negro y del villero 
mayormente en estos sectores urbanos, como también podremos observar en los mapas mentales.

El estereotipo del negro o villero o cabeza también incluye varios elementos estilizados verbales y no verbales. Se refiere a personas de estratos sociales bajos, muchas veces inmigrantes del interior de Argentina o de países limítrofes y/o habitantes de villas miserias. Se les atribuye, asimismo, preferencias estéticas, como por ejemplo, zapatillas deportivas y una gorra, $\mathrm{y}$, muy particularmente, musicales - existe una fuerte relación del estereotipo del "negro cabeza" con la cumbia villera ${ }^{15}$. En cuanto a su forma de hablar, se suele decir que hablar "a lo negro" es hablar con muchos vocativos, como por ejemplo, gato, guacho, loco, vieja, normalmente precedidos por la partícula $e$ ("eh loco"), un uso marcado de lunfardismos FN y en general, con un léxico vulgar inspirado por las letras de la cumbia villera. En el plano fonético, se relaciona el estereotipo con la pérdida de la -s final ("se comen las eses") y una variante exageradamente sorda de la palatal rehilada [ $\square$ ]. Hoy en día, a veces también se menciona una "jerga tumbera"16 (la jerga de la cárcel) como característica del estereotipo del negro de las zonas sur y oeste de la ciudad.

\section{4. "QUIERO QUE ME DIBUJES UN ESQUEMA DE LA CAPITAL...". METODOLOGÍA}

La construcción del espacio social a través de la lengua es un proceso multidimensional que ocurre en todos los niveles lingüísticos. Por lo tanto, un análisis de estas dinámicas complejas requiere una metodología multidimensional, transdisciplinar y complementaria (Ploog 2009: 282). Dentro del marco de la Dialectología Perceptual, en uno de sus trabajos más recientes, Preston argumenta que para indagar lo que personas no expertas piensan sobre lenguas y variedades, cómo las evalúan y cómo responden a variantes lingüísticas, se deberían llevar a cabo formas de investigación

15 Véase también la página de frikipedia para el estereotipo del "negro“: http://www. frikipedia.es/friki/Negro_cabeza [5/4/14]

${ }_{16}$ Sirvan como ejemplo algunos blogs individuales: http://blogs.20minutos.es/ enguerra/2010/02/05/diccionario-autumbero-a-argentino/ o http://virgulilla.wordpress. com/2009/11/05/lunfardo-villero-lenguaje-tumbero-y-otras-yerbas/ 
"both perceptually and conceptually oriented" (2010: 4). Presenta, para este objetivo, una taxonomía de métodos que distingue entre formas de revelar la percepción y las actitudes lingüísticas conscientes o inconscientes, empleando o no estímulos de lengua hablada (Preston 2010: 24). Como ya hemos explicado inicialmente, el presente trabajo se integra dentro de un proyecto de investigación más amplio, cuya metodología busca cumplir con las sugerencias de Preston y aplica diversas técnicas que pretenden revelar la percepción, las representaciones y las actitudes lingüísticas conscientes e inconscientes de los hablantes de Buenos Aires. La elaboración de los mapas mentales constituye solo una parte de todo el procedimiento metodológico llevado a cabo en el estudio.

Punto de partida para la recopilación del corpus fue la variable del barrio. Una de las principales preguntas de investigación de nuestro trabajo era en qué manera difieren la percepción del espacio urbano así como de las variedades en el uso del habla dentro de la ciudad según el barrio de residencia que, como hemos visto, no solo está muy vinculado con la estratificación económica del área urbana, sino que también actúa como factor importante en cuanto a la identidad y al estilo de vida de los hablantes. Por eso, sobre la base de la transformación urbana de Buenos Aires en el siglo xx y especialmente en las últimas tres décadas, se seleccionaron seis barrios (y partidos del primer conurbano de la Provincia de Buenos Aires) que por su historia pueden considerarse emblemáticos para ciertas formas de vida en Buenos Aires y que están geográficamente distribuidos por el área urbana. Además, estos barrios también fueron mencionados por los propios hablantes a la hora de hablar sobre las diferencias socioculturales que ellos notaban en la ciudad ${ }^{17}$ : San Isidro, Villa Urquiza, Recoleta, Caballito, La Boca, Avellaneda. De cada barrio se entrevistaron cinco hombres y cinco mujeres, nativos de la Ciudad de Buenos Aires, de alrededor de 30 años. Dado el enfoque cualitativo de nuestro trabajo, no es el objetivo disponer de una muestra cuantitativamente representante del total de la población que habita en cada uno de estos barrios. A diferencia de una investigación cuantitativa, no se busca establecer generalizaciones a partir de los datos recopilados, sino que se trata de delimitar clasificaciones y tipologías mediante un análisis profundo y detallado del muestreo. Además, puesto que estamos interesados en un estudio sincrónico, nos limitamos a un solo grupo etario de personas que nacieron todas al final o inmediatamente después de la Dictadura Militar (1976-1983). El período tras la dictadura significa para Buenos Aires un

17 Estas observaciones también provienen de Würth (2009). 
momento político, económico y sociocultural muy peculiar y forma una generación que vivió conscientemente el sistema económico neoliberal y las profundas consecuencias de su colapso. Partiendo de los criterios del barrio de vivencia y de la edad, los informantes se seleccionaron aleatoriamente, a través de la propia red de contactos ("friend of a friend" ${ }^{18}$ ).

Los mapas mentales están integrados en una entrevista de aproximadamente 1 hora y media de duración, que comienza con una primera charla semiguiada en la que se habla sobre el barrio de residencia de la persona, la ciudad de Buenos Aires, las características del español porteño y si es igual en toda el área urbana. Después de dirigir la atención del/de la informante sobre la lengua en Buenos Aires y sus primeras reflexiones o menciones sobre las diferencias que puede haber en el espacio urbano, se realizan los mapas mentales. Desde el punto de vista de la geografía social, el método del mapa mental en su forma clásica no le facilita al/a la informante ninguna información adicional (administrativa, topográfica o p. ej., referencias a puntos significativos de la urbe, como edificios conocidos, monumentos, etc.) que pueda condicionar su gráfico. Es decir, al/a la informante se le presenta una hoja en blanco sobre la que desarrollará su esquema. Nosotros procedimos de la misma manera: les presentamos a los informantes una hoja en blanco, les pedimos que dibujaran un esquema de la ciudad y que marcaran allí las zonas donde ellos notaran diferencias en la forma de hablar. En un segundo paso, se les pidió que explicaran su mapa y que argumentaran por qué habían delimitado sus áreas, y según qué criterios. Por último, tuvieron que caracterizar cada una de las áreas delimitadas con una palabra.

El hecho de que el/la informante se vea enfrentado/a a la hoja en blanco y que no tenga ningún punto de referencia para dibujar el mapa puede ser muy exigente y hasta desbordante. Además, el resultado depende mucho de la facilidad de esquematizar y abstraer de la persona entrevistada. No pocas personas incluso se expresaron en este sentido y se disculparon por su "incapacidad para dibujar" ("Ah, me mataste". "Yo para los dibujos soy cero". "Soy muy malo dibujando. Muy malo". "No tengo ni idea". "Si tuviera que dibujar la capital, en mi cabeza en realidad no sé bien cómo estaría"). Sin embargo, este método representa la forma "más pura" del mapa mental, puesto que cualquier mínima información ya significaría una influencia para el resultado. Por otra parte, es justamente la abstracción y la simplificación que puede resultar interesante, porque permite ver el grado de complejidad de la imagen que una persona tiene de la ciudad, las jerarquías sociogeográficas 
que marca (de qué tamaño dibuja los barrios, por ejemplo, o la relación de tamaño del barrio de vivencia en relación con toda el área de la ciudad), y la simplificación junto con la clasificación de las zonas delimitadas mediante una expresión, a su vez, pueden sacar a la luz varios estereotipos sociales, geográficos y lingüísticos:

The sketch map is not the mental map, but its schema that, given his abilities, the subject is able to draw. Far from being a group of unconnected, dis-united signs, the maps form structures where the elements are related to one another. In spite of distortions, omissions or additions, the map shows how each resident conceives his city. The sketch, thanks to its nature as free projection, allows the subject to express aspects of his representation of the space that could not be materialized in any other medium. They make it possible to observe the imaginary dimension of social representation, those archaic, utopian, mythical, fantastical and emotive elements linked to certain territories (Arruda y de Alba 2007; de Alba 2011: 5).

En un segundo paso, ahora sí, les presentamos a los informantes un mapa de base con las fronteras administrativas de los barrios de Buenos Aires, sobre el cual se les pidió que marcaran nuevamente las mismas zonas de diferencias en la forma de hablar. La elección de los barrios como referencia se debe al hecho de que, como hemos visto, el barrio constituye un elemento de identificación central para los habitantes de Buenos Aires y, en segundo lugar, a que nuestro objetivo era, precisamente, investigar las representaciones y los estereotipos acerca de distintos modos de hablar vinculados a determinados sectores sociogeográficos.

El proceso de trazar los dos mapas mentales fue acompañado por una charla con la persona entrevistada, durante la cual ella argumentaba su dibujo y yo preguntaba o le pedía más explicaciones al respecto. Esta metacomunicación se grabó y complementa el análisis del material gráfico.

La recopilación de los mapas mentales es seguido por un experimento de percepción en línea que nos proporciona un corpus de datos que se analizará de forma cuantitativa y complementará, de este modo, el trabajo cualitativo; una tarea de imitación, donde a partir de un texto preparado anteriormente se les pidió a los informantes que imitaran a una persona de otro barrio; una prueba de percepción con estímulos de habla natural de cinco zonas de Buenos Aires que los informantes tuvieron que ubicar en el área urbana y comentar respecto del carácter, el trabajo y el estilo de vida de la persona que estaban escuchando; y se cierra, finalmente, con una segunda charla semiguiada de reflexión sobre los temas tratados, de preguntas más explícitas sobre estereotipos y actitudes lingüísticas en la ciudad de Buenos 
Aires, sobre el papel del discurso mediático y las expresiones culturales (particularmente los estilos musicales) en la creación y el fomento de estas imágenes y creencias.

\section{LEER LA CARTOGRAFÍA MENTAL - EL ANÁLISIS DE LOS MAPAS}

En lo que sigue haremos un análisis más detallado de una selección de 6 mapas - todos del formato de la hoja en blanco- de hablantes de Recoleta y de La Boca (del total de 120 mapas del corpus). Nos limitaremos a estos dos barrios porque representan, según los hablantes (y como veremos en los mapas), barrios emblemáticos para las zonas del norte y del sur, respectivamente. Sin embargo, los hablantes cuyos mapas están incorporados aquí no necesariamente corresponden al nivel social que se atribuye a cada barrio. Estamos interesados en el componente geográfico de la percepción lingüística, por lo que nuestro principal criterio para la selección de los informantes fue el barrio de vivencia, teniendo en cuenta, por supuesto, que dentro de cada barrio puede haber heterogeneidad social o socioeconómica. Se trata de un primer acercamiento cualitativo que tiene como objetivo dar algunos ejemplos de las representaciones que cualquier habitante de estos dos barrios de Buenos Aires, sin importar su sexo, puede tener de su espacio urbano y, sobre todo, de las variedades lingüísticas de la ciudad. Para ello, nos ocuparemos, en primer lugar, del material gráfico, que estudiaremos desde una perspectiva de análisis de discurso visual, de acuerdo con un modelo desarrollado por Yvonne Riaño (2014: 16) sobre la base de los métodos de análisis visual de Rose (2012). Primero se observará la imagen como representación: ¿Qué es lo que muestra? ¿Cuál es el contexto del dibujo? ¿Qué es lo que se visualiza o no se visualiza en la imagen? Segundo, se estudiará el dibujo como práctica social: ¿En qué manera se organizan los objetos en la imagen? ¿Cuál es la relación entre ellos? ¿Se pueden distinguir jerarquías a través de la distribución espacial o el tamaño de los objetos? Estos primero dos pasos de análisis servirán de base para la interpretación de la imagen: ¿Cuáles son los significados que implica? ¿Qué importancia tienen los objetivos trazados para los informantes? ¿Por qué? Solo en segundo lugar, y como información complementaria al mapa dibujado, agregaremos los metadiscursos verbales que los hablantes enunciaron a la hora de trazar su esquema. No obstante, los mapas no se pueden estudiar totalmente independientes del metacomentario, ya que el proceso de dibujar el esquema 
fue parte de la entrevista, de una interacción con el hablante, no fue una tarea que los informantes hayan efectuado a solas. Por eso, no necesariamente se sentían obligados a poner toda la información por escrito, sino que podían dar explicaciones adicionales acerca de su dibujo.

Veamos, en primer lugar, un mapa sobre la hoja en blanco de un hablante masculino, de 30 años, del barrio de Recoleta, mencionado muy a menudo como emblemático de un sector social más alto y un estilo de vida elitista ${ }^{19}$. El informante es periodista y actualmente está coordinando el área de prensa de escuela que depende del Gobierno Nacional. Casi toda su vida vivió en Recoleta y a la pregunta de si se identifica con el barrio, contesta: "Mirá, te digo la verdad. Yo soy peronista. Y la Recoleta es muy, digamos, contrapuesta al peronismo. Y soy militante. Así que, peor todavía. Pero la verdad que viví toda mi vida ahí, le tengo cariño al barrio. O sea, no puedo no tenerle cariño". Se percibe entonces cierta ambigüedad en el hablante, quien por un lado se distancia y políticamente hasta se opone al sector social de Recoleta, pero a la vez creció en este barrio, se identifica con él y "no puede no tenerle cariño". Esta situación hay que tenerla en cuenta para el análisis del mapa que dibuja:

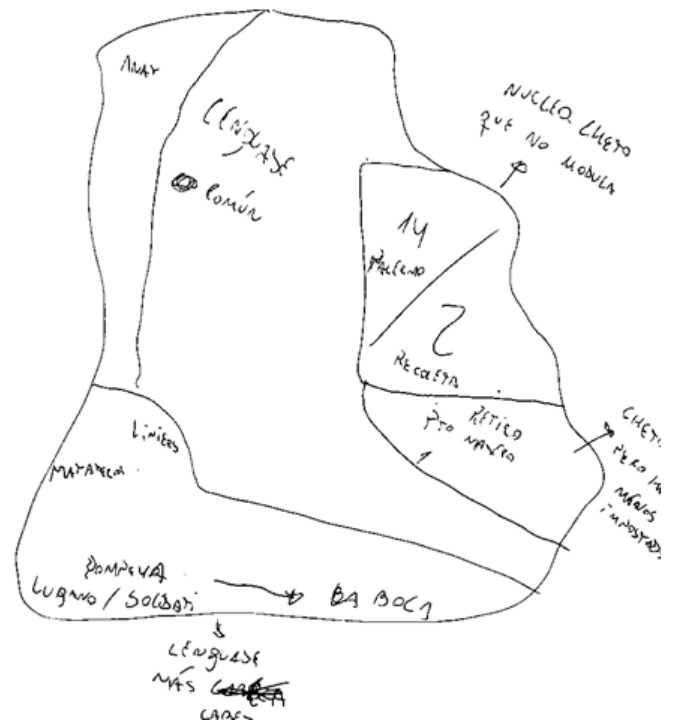

Mapa 1: informante masculino, 30 años, periodista, Recoleta

19 Para más información acerca del barrio: http://www.buenosaires.gob.ar/areas/barrios/ buscador/ficha.php?id=28 [2/4/14] 
Salta a la vista que se hace una división de zonas en el noreste, en el centro y en el sur. En el noreste se delimitan los barrios de Palermo y Recoleta como una zona pegada a otra que incluye Retiro y Puerto Madero (los números 14,2 y 1 se refieren a las comunas a las que pertenecen estos barrios). En el área central, el más grande, no delimita ningún barrio, solo marca una franja en el oeste que no especifica más. En el sur distingue los barrios de Liniers, Matanza, Pompeya, Lugano, Soldati y, marcado con una flecha, La Boca, pero los incluye todos dentro de una misma zona sur-oeste. Dado que el hablante viene de Recoleta, no sorprende que ahí su mapa sea más específico y que marque las fronteras con los barrios lindantes, mientras que en las áreas más ajenas generaliza mucho más. En cuanto al lenguaje, la zona de Palermo y Recoleta se caracteriza como "núcleo cheto que no modula". Retiro y Puerto Madero, en cambio, aunque también caracterizados como cheto, se señalan con un "habla menos impostado". Es decir, Recoleta junto con Palermo es la zona considerada más emblemática para la forma de hablar "cheta". En el centro ubica un "lenguaje común", o sea, no marcado, y en el sur-oeste nota un lenguaje "más cabeza". A la hora de dibujar, el hablante precisa su esquema dando explicaciones más concretas:

$$
\begin{aligned}
& \text { Sí bueno. Sí hay. Hay diferencias. Sí sí. Vos tenés, qué sé yo, todo lo que } \\
& \text { es la zona norte, tiene una tonada más cheta. No sé cómo... explicarlo, } \\
& \text { pero. Se pronuncia más la ese, eh... hay palabras, qué sé yo, es como, } \\
& \text { se modula menos, la palabra, no? Me da esa sensación de como que... } \\
& \text { se habla "sí le dije a Facu que tal y tal cosa bolo", [imita] o sea... "qué } \\
& \text { bueno que estuvo" viste, es un tono más... más Mauricio Macri, digamos, } \\
& \text { últimamente. Y después hay zonas más... en las zonas más cabezas } \\
& \text { digamos. Se habla más parecido al conurbano "eh, amigo, la concha de } \\
& \text { tu madre", [imita] digamos eh... más tumbero el el lenguaje. Y después } \\
& \text { en el medio tenés una zona de clase media que es más intelectualoide } \\
& \text { como habla, por ahí. [...] }
\end{aligned}
$$

Tal como lo dibuja en el mapa, el hablante delimita tres zonas generales con su respectiva forma de hablar: en toda la zona norte ${ }^{20}$ nota una "tonada más cheta", que precisa diciendo, en primer lugar, que "se pronuncia más la ese". Distingue la zona norteña en relación con los demás barrios (sobre todo los del sur), muy frecuentemente asociados con una mayor tendencia a elidir la -s a final de palabra. Es decir, en el norte, en la forma de hablar

20 Suponemos que con la denominación zona norte se refiere, en este caso, tanto a los barrios que quedan en el norte del área de la capital como a la franja suburbana norteña del conurbano, comúnmente llamada Zona Norte. 
del cheto, a diferencia del sur, sí se pronuncia la ese. Después constata que "hay palabras", o sea, se refiere también a un léxico característico de esta zona, aunque no da ejemplos más concretos. Y por último, diciendo que "se modula menos" se mueve en un plano fonético y suprasegmental. Cuando imita la tonada la compara con "un tono más Mauricio Macri ${ }^{21}$ ", el actual jefe del Gobierno de la Ciudad, quien se mencionó en varias de nuestras entrevistas como representante de una forma de hablar "cheta". No sorprende que el hablante muestre una conciencia bastante desarrollada respecto de la forma de hablar que él denomina "cheta", porque es la variedad urbana con la que supuestamente está más en contacto en su barrio, pero a la vez se distancia de este lenguaje, lo imita, y lo relaciona con el jefe del Gobierno de la Ciudad, cuya posición política tampoco comparte.

Por el otro lado, en las zonas que denomina "más cabeza", opina que la forma de hablar se parece más a la del conurbano y que se trata de un "lenguaje más tumbero". Se refiere, en este caso, tanto a una determinada entonación y fonética ("un tono" o "una tonada") como también a ciertas expresiones léxicas muy vulgares, de las que menciona algunas en su imitación (p. ej., "la concha de tu madre").

Finalmente, pasa a tratar el sector medio, que para él constituye la mayoría de los hablantes y que "habla más normal", pero también "más intelectualoide". Atribuye pues al sector medio una forma de hablar más común, menos estilizada, pero, según su opinión, un poco pseudo-intelectual. Es decir, igualmente no se inscribe del todo en el área del centro, sino que muestra igualmente un leve distanciamiento o una perspectiva desde afuera, muy probablemente debido a su barrio de origen. De todos modos, las variedades del centro son mucho menos marcadas y los estereotipos se refieren principalmente al norte y al sur.

El segundo mapa que queremos analizar es el de una hablante femenina, también de Recoleta, periodista, de 33 años. La persona vivió el mayor tiempo de su vida en Recoleta, primero con su familia y después sola, pero hace tres años se mudó a Palermo con su pareja. Hoy en día, como afirma en la entrevista, se identifica más con Palermo que con Recoleta, porque es un barrio más tranquilo, más verde, de casitas más bajas. Sin embargo, en su dibujo no menciona este barrio:

${ }^{21}$ Véase su página personal http://www.mauriciomacri.com.ar/ y de su partido, el PRO: https://pro.com.ar/ [10/4/14] 


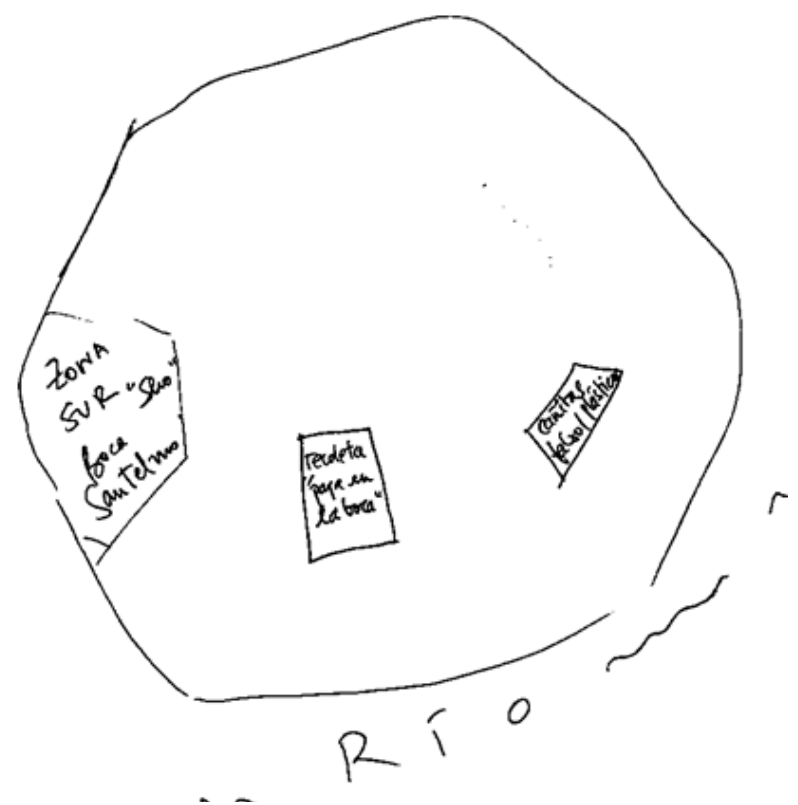

Mapa 2: informante femenina, 33 año, periodista, Recoleta

Lo que se ve es un círculo con la referencia geográfica de la orilla del Río de la Plata (es decir, el norte geográfico estaría en este dibujo a la izquierda). Dentro del círculo, se distinguen tres zonas: a la izquierda, un área denominada "zona sur", incluidos los barrios de La Boca y San Telmo. La forma de hablar de esta zona la caracteriza la informante mediante la palabra "sho", con lo que se refiere a una variante estereotipada más sorda de pronunciar la palatal rehilada, en oposición a la realización de la palatal en otras partes de la ciudad. Después, en el medio, delimita un cuadro para el barrio de Recoleta, cuya forma de hablar caracteriza con "papa en la boca". Tercero, más hacia el norte, dibuja otro cuadro para el barrio de Cañitas, una denominación no oficial para un sector de muchos negocios, bares y restaurantes dentro del barrio de Palermo ${ }^{22}$. Los atributos con los que la hablante caracteriza esta zona específica son "falso" y "plástico". Para entender el significado de estas denominaciones hay que recurrir a las explicaciones acerca del dibujo: 
(2) Sí sí, no la tengo muy clara... No sé (se ríe). Acá está el río. Eh bueno, por acá está Recoleta, yo qué sé, por acá. No, acá es notorio. Cuando vas a Recoleta, es notorio. Te pongo "papa en la boca". Ehm... Bueno, por ahí la zona de La Boca y eso es una zona más humilde, tampoco lo tengo tan claro como hablan en La Boca, eh, pero... Yo. A ver, después a ver, por Las Cañitas... a Las Cañitas lo veo como plástico. Muy plástico. No sé si en la forma de hablar, pero como... como que en... acá está, acá es, en Recoleta también lo veo como un barrio plástico, pero... Las Cañitas más. Como mucho, mucho operado, viste? Mucha operación de cirugía estética. Pero no sé si tiene que ver con la forma de hablar.

Antes de empezar a dibujar, la hablante se disculpa por no tener una imagen muy clara de la capital. Después, empieza con el río como referencia geográfica y ubica Recoleta, su barrio de origen, en el centro, diciendo que ahí hay una diferencia notoria en la forma de hablar y que pone "papa en la boca", metáfora que se repite para clasificar la variedad lingüística de esta zona. Siguiendo con su dibujo, traza La Boca, que caracteriza como zona más humilde, destacando, como hemos visto, la realización más sorda de la palatal. Luego hace un salto a Las Cañitas, de donde tiene un estereotipo de "plástico", de "mucha cirugía estética" que, según ella, se ve también en Recoleta, pero de forma mucho más palpable en Las Cañitas. Como dice ella, esta estilización no se refiere directamente a una determinada forma de hablar, pero sí a un estereotipo social que se relaciona indirectamente también con cierto uso de habla.

Un poco más adelante, explicando todavía las diferencias lingüísticas que ella nota en la capital, da un ejemplo:

(3) por ejemplo en eh... el hermano de una amiga, fuimos al cumpleaños de una amiga mía y estaba el hermano y no podía creer la forma en que hablaba, entendés, porque... y genera mucho rechazo esa forma de hablar, porque... es como que... parece que la persona... para quien no pertenece es como que... parece que el otro quisiera generar una distancia. Yo, que estoy un poco del otro lado, entiendo que... "bueno, aprendiste a hablar así, no es tu culpa", es como... es tu forma de hablar, así como en otros barrios el pronun... se... no sé... se pronuncia más la she o la ese, o, o no se pronuncia la ese, se comen las eses, viste, como que...

Cuenta de un cumpleaños de una amiga (en Recoleta) cuyo hermano tenía, según ella, una forma muy extrema de hablar, a tal grado que ella misma, que también es de Recoleta, no lo podía creer. Dice que es un modo de hablar que genera rechazo para "alguien que no pertenece", que parece que la persona que habla quisiera generar una distancia. Queda muy evidente el factor de pertenencia, de que si una persona es parte del grupo le va a 
resultar común la forma de hablar, no la va a percibir marcada, pero para alguien que no pertenece causa mucha distancia y mucho rechazo. Al mismo tiempo, la hablante también defiende y justifica al hablante del que cuenta, porque si aprendió a hablar así, no es su culpa, así como en otros barrios "se pronuncia más la she" o "no se pronuncia la ese". Es decir, que la hablante, moviéndose entre diferentes grupos sociales o, como ella dice, "estoy un poco del otro lado", percibe los rasgos lingüísticos marcados, se distancia de ciertas formas de hablar pero a la vez las justifica, porque tampoco le son tan ajenas. Una vacilación que puede indicar un posible conflicto de identificación social.

Veamos ahora un tercer mapa de Recoleta, en el que también se hacen visibles los estereotipos fonéticos de la realización de la palatal, por un lado, y la pérdida de la -s final, por otro. El hablante es masculino, de 27 años, estudia ingeniería y pasó toda su vida en Recoleta, hasta que a los 26 se mudó a Núñez, un barrio más en el norte de la ciudad. Dice de Recoleta que es un "barrio de viejos" y que "los precios están excesivamente caros" y que le gusta vivir en Núñez, pero que tiene toda la familia en Recoleta y que no quiere desligarse de ese barrio tampoco. Su mapa se distingue de los que hemos visto hasta ahora:

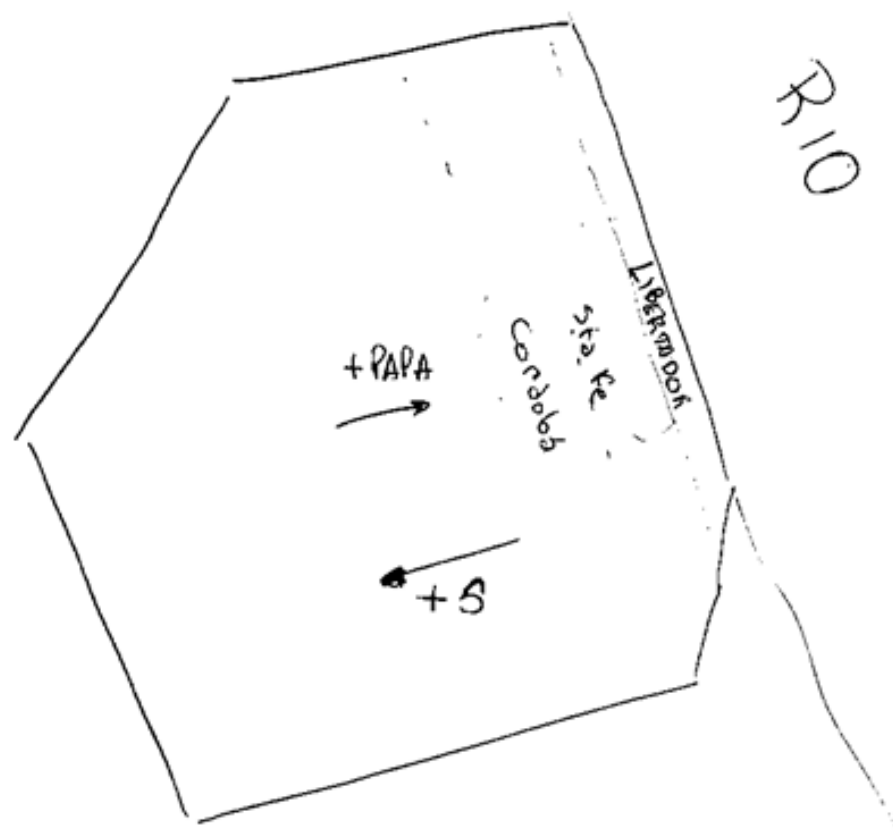

Mapa 3: informante masculino, 27 años, estudiante de ingeniería, Recoleta 
El hablante parte igualmente del Río de la Plata como referencia geográfica. Sin embargo, a diferencia de muchos otros, después no hace una división en barrios, sino que traza las avenidas principales como escalas de un contínuum de desigualdad social y lingüística. Aunque vacila un poco con las avenidas que quiere mencionar y su dirección en el mapa, como se desprende de su explicación, igual tiene una representación distinta del espacio urbano, centrada en las principales vías de tráfico y no en la división barrial. En su dibujo también marca un contínuum de dos rasgos lingüísticos estereotipados: la "papa (en la boca)" y la -s final. Mediante dos flechas expresa, por un lado, que en dirección hacia el río, más "papa" hay en la forma de hablar. Y por otro lado, con otra flecha que va desde el río hacia el oeste de la ciudad, indica "+s", "más eses en la terminación", aunque muy probablemente se haya confundido y haya querido decir "menos -s" o, tal vez, "más caída de la $-\mathrm{s}$ en la terminación", porque sería muy raro que se expresara completamente en contra del estereotipo común de que hacia el oeste y el sur cae más la - s final.
Así... Todo este sector es el Río de la Plata, ¿no? Todo ese... es como... las formas de hablar para mí van junto con el poder... precio inmobiliario. A medida que vos te alejás del río, va cayendo el precio, y van cambiando las formas. Yo lo que siempre digo, son como... ponele acá tenés Libertador. Es como vas pasando líneas. Libertador, eh... Libertador no es la mejor opci... eh, el mejor ejemplo. Eh... Callao... no bueno, volvamos a Libertador. Libertador, Santa Fe, Córdoba, Corrientes, Rivadavia, entonces a medida que vos vas cruzando las avenidas, cada vez más temprano tenés que volver a tu casa (se ríe). Más o menos. Sí. Yo lo separaría así. [...]
Y... yo pondría, para acá, más eses. Más eses en la terminación. Eh... pero es muy general esto. Ehm... para acá, y más específicamente acá, eh... más papa.

En su comentario del mapa, manifiesta también un estereotipo social bastante acentuado: indicando que "a medida que vos vas cruzando las avenidas, cada vez más temprano tenés que volver a tu casa", acompañado de risas, muestra que en su visión de la ciudad aumenta la inseguridad gradualmente desde la zona que linda con el río, considerada como la más segura, hacia el sur-oeste de la ciudad. Siendo del barrio de Recoleta y actualmente viviendo en Núñez, el hablante se mueve sobre todo en la franja norte de la capital -la mencionada Avenida del Libertador es una de las avenidas principales de esta zona y une el barrio de Retiro con Núñez. Es el área que conoce, donde se siente seguro, y mientras más se aleja de ahí, más lo desconoce y más miedo le da, sin dar más especificaciones. El tema de la 
inseguridad y el miedo a moverse en ciertas zonas de la ciudad se presenta de forma recurrente en nuestras entrevistas, hecho que se debe también a que el tópico actualmente está muy presente en la política y en los medios de comunicación de Buenos Aires ${ }^{23}$.

Pero ocupémonos ahora de los mapas mentales de hablantes de otro barrio, que justamente se considera muchas veces como representante del sur, de un estrato social más bajo y, por tanto, de otro estereotipo: La Boca. En primer lugar, un mapa de una hablante femenina, maestra de secundario, de 30 años. La persona vivió toda su vida en el barrio, si bien tiene mucha movilidad dentro de la capital, debido a sus estudios y diferentes trabajos. A la pregunta de qué es lo que distingue su barrio, contesta:

$$
\begin{aligned}
& \text { Y... la pertenencia. Yo siempre pensé eso, que es como un barrio de } \\
& \text { pertenencia muy fuerte. No solo La Boca, sino los barrios alrededor. Como } \\
& \text { que la gente que vive ahí se queda ahí, no hay... no tienen aspiraciones } \\
& \text { de irse a otro lado. Nací, nacés ahí, te morís ahí, básicamente. Sí. }
\end{aligned}
$$

Se nota pues una identificación muy fuerte con su barrio de vivencia, pero un conocimiento bastante amplio del mapa de la capital y de los barrios porteños que, seguramente, se debe a su movilidad geográfica y, tal vez, también a su formación profesional como maestra de historia:

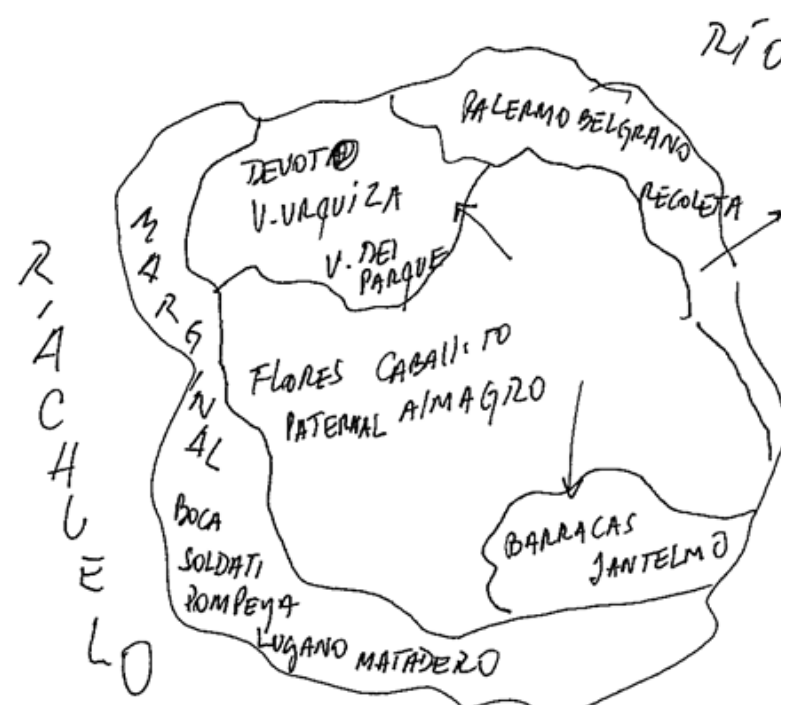

Mapa 4: hablante femenina, 30 años, profesora de historia, La Boca

23 Véase, al respecto Janoschka (2002). Para el tema del miedo en espacios de frontera, consúltese Reguillo (1998). 
$\mathrm{Al}$ igual que en los mapas anteriores, aparece la referencia geográfica del Río de la Plata en el sureste, complementada, en este caso, por la referencia del Riachuelo ${ }^{24}$ en el suroeste (aunque, geográficamente, éste se ubicaría un poco más en el sur) que representa la frontera natural entre los barrios del sur de la capital con los partidos de la provincia de Buenos Aires. Dentro de la capital, esquematizada con la forma de un círculo, la hablante hace su división también a partir de los barrios. Así, distingue una zona constituida por Palermo, Belgrano y Recoleta en el noreste, Devoto, Villa Urquiza y Villa del Parque en el noroeste, Flores, Paternal, Caballito y Almagro en el centro, Barracas y San Telmo en el centro-sur y, por último, una franja que se extiende a lo largo de la frontera sur-oeste de la capital, denominada "marginal", constituida por los barrios La Boca (que no señala de modo especial), Soldati, Pompeya, Lugano y Mataderos (aunque el orden de anotación no corresponde a su ubicación geográfica). Es evidente, pues, que la representación del espacio urbano de esta hablante, como ya lo hemos visto en algunos de los casos anteriores, está fuertemente anclada en la división barrial de la ciudad. Veamos ahora de qué manera comenta su mapa:
Y el tema del lenguaje, a ver, cómo podría decirlo... Eh... Y... yo creo que todo responde a lo social, ¿no?, o sea, porque el lenguaje, o sea, de esta gente de clase alta, por así decirlo, es como un... que ni siquiera es un lenguaje refinado, ¿no? [...] quizás una persona de Palermo, no sé cómo explicarlo, tiene como... sí, como variaciones, como dialectos, creo, no sé si se dice así, pero es como un dialecto de esa zona, ¿no? El "boludo", el "sorry", fue una época, ¿no? Como el el... no sé. Lo definiría así. Y bueno esta zona, acá te das cuenta realmente la falta de educación, ¿no? [...] como que todo es "eh amigo, dame una moneda" eh o... viste, esta cosa de "me como las eses", eh, "pronuncio mal las palabras", ¿no?

La hablante subraya reiteradamente que la forma de hablar responde a lo social y le da importancia fundamental al grado de formación que una persona tiene para su capacidad de "hablar bien". Influenciada por su profesión, refiriéndose a los barrios que ella denomina "marginales", especifica que falla la educación y que por eso a la gente le cuesta armar oraciones correctas. Dice que ahí es todo "eh amigo, dame una moneda", que "se comen las eses" y "se pronuncian mal las palabras. Por el otro lado, dice que la clase alta tiene un lenguaje distinto, que primero quiere caracterizar como refinado, pero corta la frase y dice "que ni siquiera es un lenguaje refinado". Es decir, para

24 http://www.atlasdebuenosaires.gov.ar/aaba/index.php?option=com_content\&task=vie w\&id=347\&Itemid=188 \&lang=es [3/4/14] 
ella la gente de clase alta no habla "mejor", sino que una persona de Palermo (que, por tanto, equipara con una persona de clase alta) tiene "variaciones" o "dialectos". Menciona, por ejemplo, las palabras boludo o sorry como típicas de esta zona en un determinado momento. En la reflexión de la hablante se nota una conciencia alta de las diferencias sociales y de cómo estas repercuten en la forma de hablar, intentando, de este modo, no caer en los estereotipos comunes. No muestra una actitud negativa o de rechazo hacia ninguno de los dos sectores, sino que explica la forma de hablar de la clase alta a través de una cuestión de pertenencia, mientras que en el lenguaje del sur se hace evidente la falta de educación.

Otro mapa que muestra de manera muy evidente los estereotipos opuestos de norte y sur es el de una hablante femenina de 33 años de La Boca. La persona es docente en una escuela pública y hace 10 años que vive en La Boca, después de haber vivido durante mucho tiempo en la Zona Sur de la provincia de Buenos Aires. Como característico de La Boca también menciona que los habitantes de este barrio se quedan viviendo en el barrio, no se van a otros lugares, que "genera como una cosa de pertenencia". Por su formación profesional, la informante también presenta un grado relativamente alto de movilidad geográfica dentro de la capital, la cual, sin embargo, no se refleja de la misma manera en su mapa:

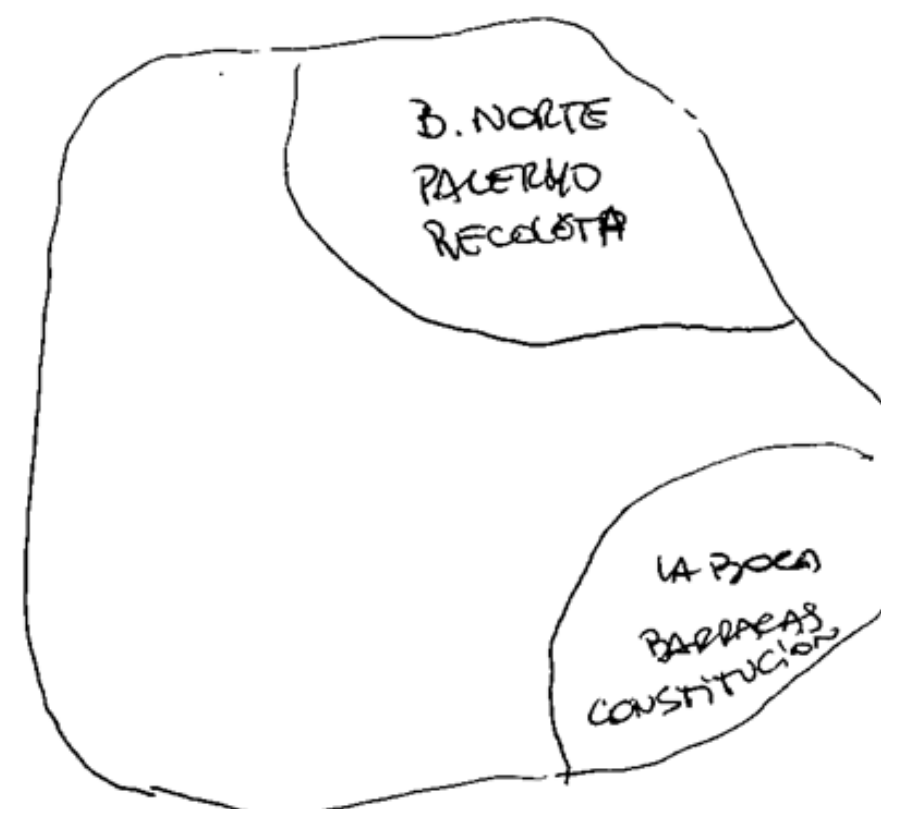

Mapa 5: informante femenina, 33 años, docente en una escuela pública, La Boca 
Dentro de la capital, que se representa mediante un círculo, vemos otra vez una división de una zona en el noreste que contiene Barrio Norte, Palermo y Recoleta (aunque, como hemos visto, la denominación no oficial de "Barrio Norte" incluye gran parte de Recoleta) y, por el otro lado, una zona en el sureste constituida por La Boca, Barracas y Constitución. Toda el área del medio no está clasificada.

Veamos, ahora, algunos fragmentos de su comentario respecto del mapa:

Y no sé, ponele por acá por el barrio lo que se estila mucho es el lenguaje así pibe chorro. "Eh gato, eh no sé qué" [imita], bueno, este... [...] Por acá por el barrio yo veo, no sé aparte estoy muy influenciada por los chicos de la escuela y que tienen más ese lenguaje así de la cumbia y todo eso.

En primer lugar, la hablante se refiere a la forma de hablar de su propio barrio ("por acá por el barrio") y menciona que "se estila mucho el lenguaje así pibe chorro". Es decir, presenta el uso de la lengua como parte de un estilo, un modelo a seguir, el del "pibe chorro", otro término estereotipado que está muy relacionado con el del negro o villero, pero se refiere más a un grupo de jóvenes (masculinos) ladrones ${ }^{25}$. El término se popularizó también debido a un grupo de cumbia villera que se llama Los pibes chorros. Según la hablante, la cumbia y las letras de los temas de cumbia tienen mucha influencia en la forma de hablar de los jóvenes de su barrio. Menciona, por ejemplo, la palabra gato, término despectivo y con connotación de agresividad que hoy en día se usa con función de vocativo. Nótese la partícula "eh" que casi siempre acompaña los vocativos despreciativos.

En cuanto al modo de hablar de otros barrios, la hablante duda y no quiere entrar en prejuicios, lo cual es un índice de que hay un estereotipo respecto de ese sector que es conocido y sufre estigmatización entre los hablantes porteños. Menciona, luego, que en esas zonas hay pocas expresiones que pertenecen al lunfardo, de lo que se desprende que el lunfardo, que tiene sus orígenes en el sur de la ciudad, se sigue asociando con esos barrios ${ }^{26}$. Además, pasando al nivel fonético, la hablante señala una pronunciación "rara" o "arrastrada" de la ese, rasgo mencionado también por otros hablantes, a

25 En la ya mencionada página frikipedia, se registra el pibe chorro como un tipo de villero: http://www.frikipedia.es/friki/Villero [3/4/14].

26 Sin embargo, a pesar de su arraigo en el sur de la ciudad, muchas voces del lunfardo se extendieron sobre todo el territorio urbano y a todas las capas sociales (véase Teruggi 1979). Habría que realizar un análisis más profundo de cuáles son los lunfardismos que se generalizaron en el español porteño y perdieron su marca socio-geográfica, y cuáles todavía mantienen esta connotación. 
veces con la indicación de que "se parece más a la ese de España", o sea, se percibe más como variante alveolar. Y por último, volviendo al léxico, dice que en las zonas norteñas no es tan frecuente el uso del "che" pero sí, en cambio, el emplear las muletillas "tipo" y "tipo que", que ya hemos mencionado para el estereotipo del cheto.

(8) Se nota por... Qué sé yo, a ver cómo decirlo que no sea un prejuicio. No sé, se nota más en... no sé, no hay expresiones, muy pocas expresiones que de lo que parece tiene como el lunfardo, qué sé yo. Y después hay como una pronunciación de la ese que es muy rara, que no sé un tipo más cercano a la "shhhh" [imita], no sé. Como una pronunciación más arrastrada de la ese, este... Y no usar el "che", casi nada, casi nada, eso seguro. Y... qué otra cosa, y el "tipo", "tipo que"...

El último mapa que queremos someter a nuestro análisis es el de un informante masculino, de 32 años, también de La Boca. El hablante estudió para cocinero y hoy en día trabaja haciendo eventos de cocina en proyectos sociales. También muestra una fuerte sensación de pertenencia respecto del barrio, que él hasta llama "enamoramiento". La persona también tiene bastante movilidad social, sobre todo conoce muy bien el norte de la capital porque juega al rugby en un club en el norte. Veamos ahora su dibujo:

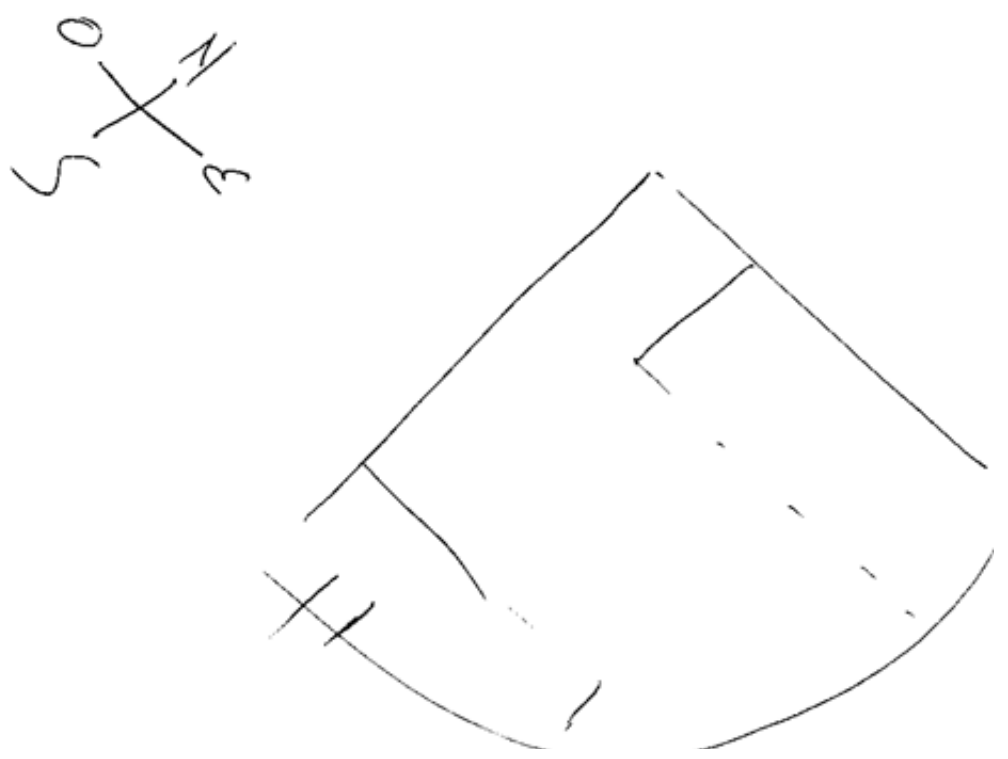

Mapa 6: informante masculino, 32 años, cocinero, La Boca 
A primera vista, el esquema parece bastante rudimentario. Tiene la forma de un cuarto, con una línea recta en el oeste, otra línea que delimita el norte, y una línea más redonda hacia el sureste, hacia el río. Las dos líneas cortas en el sur representan el "puente Avellaneda" que (desde La Boca) comunica la capital con Avellaneda en la zona sur de la provincia de Buenos Aires y que, por tanto, constituye una referencia importante para el hablante de $\mathrm{La}$ Boca. Ya no sorprende la delimitación de zonas que realiza en su mapa: de forma relativamente abstracta, marca una zona rectangular en el sur y otra parecida en el norte, lo cual comenta de forma explícita en su comentario:

$$
\begin{aligned}
& \text { Y... norte sería, más o menos... Sería este y oeste. Por acá el río, y el } \\
& \text { norte... No sé exactamente dónde terminaría, ¿no? Pero más o menos... } \\
& \text { De esta parte para allá, hacia el norte sería un poco... Pasa que también } \\
& \text { abarcaría Palermo, viste, partes central y centro-norte de la capital. Y } \\
& \text { después el sur, una cosa así, por acá, viste, lo más pegado al río, más } \\
& \text { cerca de la provincia, la parte de Avellaneda, teniendo en cuenta que el } \\
& \text { mapa está bien... Acá estaría el puente. Todo para estos lados... Igual... } \\
& \text { qué sé yo, no sé cómo va Palermo en el diagrama este que te hice en el } \\
& \text { dibujito, más o menos es algo así. }
\end{aligned}
$$

Se repite pues la división norte-sur con una zona central no muy marcada, como se ha podido observar en varios casos que hemos analizado en este trabajo. En cuanto al uso del habla, también presenta una estilización palpable entre norte y sur:

(10) Tenés, no sé, el que habla muy cheto "muy, ¿no?, así" [imita] en general se lo identifica con el norte. Después está el que habla medio cabeza, viste, "eh pibe" no sé, "eh guacho" [imita] se lo identifica más con el sur, qué sé yo, puede ser, pero sí, sí hay maneras de hablar por zonas.

$\mathrm{Al}$ que habla "muy cheto", que imita tratando de pronunciar un tono más nasal, lo relaciona específicamente con el norte de la ciudad, oponiéndolo a una persona que "habla medio cabeza" y que imita mencionando sobre todo características léxicas y que relaciona con el sur. Siendo el hablante de un barrio del sur y moviéndose con frecuencia en las zonas norteñas, muestra una conciencia desarrollada de los estereotipos lingüísticos. Afirma que sí hay maneras de hablar por zonas, y lo demuestra con los propios estereotipos que menciona e incluso imita, sin mencionar rasgos concretos, no obstante. El uso del aumentador muy para clasificar lo que él denomina cheto a diferencia del adverbio medio para referirse a la forma de hablar cabeza indica que hay un distanciamiento más grande hacia el norte, que correspondería con la identificación fuerte que presenta respecto de su barrio de vivencia. 


\section{CONCLUSIÓN}

Si bien en el presente trabajo hemos presentado solo un muestreo muy limitado de nuestro corpus, varios son los aspectos que se pueden desprender de este primer análisis cualitativo de los mapas dibujados y los respectivos metacomentarios de hablantes de dos barrios porteños, Recoleta y La Boca. En primer lugar, se muestra de manera evidente que la representación del espacio urbano bonaerense está estrechamente anclada en los barrios. Con la excepción de un informante, todos los hablantes, tanto los de Recoleta como los de La Boca, trazaron o anotaron la referencia de uno o varios barrios, y en casi todos se mencionan los dos, o al menos se hace la oposición entre norte y sur. Es decir, no hay casos donde se haya dibujado solo uno de los dos barrios, como tal vez se hubiese podido esperar, ya que no sorprendería que el propio barrio fuera la referencia primordial, representado en tamaño más grande, por ejemplo. Para las dos zonas se mencionan, además, barrios enigmáticos o prototípicos: Recoleta, junto con Palermo, Belgrano y Núñez en el norte, y La Boca, Barracas y San Telmo para el sur. No obstante, muchas veces en el sur también se incluye parte de la franja oeste, marcando una zona marginal más amplia. Está claro que la división espacial se basa en la diferencia de estatus socioeconómico. Sin embargo, hay barrios que son claramente más marcados - por tanto, salientes- que otros en la representación socioespacial que los habitantes tienen de su ciudad y de las identidades urbanas. De igual manera actúa la estilización social y lingüística: se establece una oposición entre norte y sur, entre sectores altos y bajos, entre los que hablan "con una papa en la boca" y los que "se comen las eses". Para referirse a los habitantes de los barrios norteños existe un estereotipo totalmente convencionalizado del cheto que tiene un modo de hablar "más nasal" ("la papa en la boca"). Casi todos los informantes lo marcaron en el mapa o lo mencionaron explícitamente en su comentario. Parece que no hay mucho escrúpulo en estilizar a este sector social. Lo que llama la atención es que los mismos hablantes de Recoleta lo mencionan, a veces incluso de manera más tajante, con solo pocas justificaciones en algunos casos, lo cual demuestra su conciencia al respecto. Por un lado, puede ser que intenten distinguirse del estereotipo, creando distancia frente a la forma estilizada. Por el otro lado, también es posible que se identifiquen con este grupo, conscientes de su carga social, justificándose y reforzando su sentimiento de pertenencia. Esto corresponde, en cierto grado, con el grado de identificación con los respectivos barrios. Mientras en La Boca observamos una sensación de pertenencia muy fuerte, mencionada reiteradamente como un rasgo característico del barrio, la vinculación con Recoleta parece un 
poco más ambigua, y el cariño que los habitantes tienen hacia su barrio a menudo entra en conflicto con un distanciamiento del sector social que predomina en esta zona.

Los rasgos lingüísticos con los que se caracteriza la forma de hablar del norte son la nasalidad que, en nuestra opinión, tiene que ver con elementos suprasegmentales y la calidad vocálica (se registra a menudo una variante más abierta de la vocal $\mathrm{final}^{27}$ ), una realización más arrastrada de la $-\mathrm{s}$ (que se parece a la $-\mathrm{s}$ alveolar peninsular), una pronunciación menos sorda de la palatal rehilada ([ $\square]$ en oposición a una $[\square]$ muy marcada) y, en el nivel léxico, el uso más frecuente de anglicismos y de muletillas como, por ejemplo, tipo $q u e$. En lo que se refiere al sur, la denominación del estereotipo no recae en una sola palabra prototípica. Se ve que se tiende a evitar el término negro, pero sí se usa la expresión cabeza, que también implica una noción despectiva. También se recurre a denominaciones más neutras, como "esta zona" o "sectores más bajos". Se relaciona este grupo con un "lenguaje tumbero", un "lenguaje de la cumbia" o "un lenguaje pibe chorro", que se caracteriza sobre todo por el uso de determinado léxico (influenciado por las letras de la cumbia y la jerga de la cárcel, y determinados lunfardismos que siguen teniendo la connotación de ser de los ambientes más bajos), como, por ejemplo, gato, guacho, pibe, etc. y la pérdida de la -s final. Igual como en el caso de los hablantes de Recoleta que mencionan el estereotipo del cheto, los de La Boca también son conscientes de la estilización de la forma de hablar del sur ("por acá por el barrio lo que se estila mucho es el lenguaje así pibe chorro") y lo califican en varias ocasiones como "mal hablar" debido a la falta de educación en esta zona.

Tal como lo hemos definido inicialmente, la identidad urbana se constituye por un conjunto de elementos - estéticos, verbales y espacialesque en el sistema de distinción dentro del espacio urbano se manifiestan y se acentúan siempre en oposición a un "otro". El sentimiento de pertenencia a un grupo siempre implica la existencia de otro grupo del que uno se distancia. Esto explica el hecho de que todos los informantes incluidos en este trabajo hayan mencionado los dos opuestos de la dicotomía norte-sur. El uno siempre se entiende en relación con el otro.

Además, también hemos visto que algunos de los elementos que constituyen las diferentes identidades o los diferentes estilos de vida están más marcados que otros y se usan de manera constante y reiterada

27 La influencia de una variante más abierta de la vocal final para la percepción de una forma de hablar "nasal" es una hipótesis nuestra que queda por confirmar. 
para estilizar los dos grupos. La percepción de determinados aspectos o fenómenos como salientes para ciertos sectores es un proceso que se desarrolla sobre la base de un sistema de representaciones geosociales que los individuos adquieren por su entorno social y que actúa como filtro para su imagen del espacio urbano y los fenómenos que perciben y evalúan de modo positivo o negativo. No debe subestimarse aquí el papel de los medios de comunicación. La presencia de estereotipos comunes que se expresan por una gran cantidad de hablantes de muy distintas zonas de la ciudad casi literalmente, como, por ejemplo, la metáfora papa en la boca o los vocativos vulgares loco, gato, guacho, etc. precedidos por la partícula $e h$ denota que, aparte del discurso popular extendido en el espacio urbano, también haya un discurso mediático que fomenta dichos estereotipos ${ }^{28}$. Sin embargo, el marco de este trabajo no permite entrar en detalle en esta cuestión. Aquí nos hemos centrado en la imagen que hablantes de dos zonas urbanas muy distintas tienen de la ciudad de Buenos Aires, de qué forma esquematizan esta imagen sobre papel, cuáles son las representaciones geosociales que se hacen visibles en este dibujo y cómo se estilizan las diferencias geográficas, sociales y lingüísticas que los hablantes perciben. Hemos presentado pues un muestreo de lecturas de la ciudad, que aunque procedan de habitantes de entornos muy distintos, dejan observar muchos paralelismos y un imaginario compartido de su espacio urbano.

\section{REFERENCIAS BIBLIOGRÁFICAS}

Alba, Martha De. 2004. Mapas mentales de la ciudad de México: una aproximación psicosocial al estudio de las representaciones espaciales. Estudios Demográficos y Urbanos 55: 115-143.

2009. Representaciones sociales y el estudio del territorio: aportaciones desde el campo de la Psicología Social. Cuajimalpa: Laboratorio de Análisis Socioterritorial Universidad Autónoma Metropolitana.

2010. Representaciones sociales y el estudio del territorio: aportaciones desde el campo de la Psicología Social. En Salomón González (coord.). La integración de la dimensión espacial en las ciencias sociales y humanidades: Un proyecto docente interdisciplinario, UAM-Cuajimalpa, México. http://www.cua.uam.mx/csh/ebook/.

28 Véase, a modo de ejemplo, las ya mencionadas publicidades de las papas Lay's, que ilustran de manera impresionante el lugar común de la "papa en la boca" o los videos cómicos de Peter Capusotto: www.youtube.com/user/petercapusottotv [14/7/14]. 
2011. Social Representations of Urban Spaces: A Comment on Mental Maps of Paris. Papers on Social Representations 20: 1-14.

Arruda, Alba y Martha de Alba (eds.). 2007. Espacios imaginarios y representaciones sociales. Aportes desde Latinoamérica. Barcelona: Anthropos-Uami.

Auer, Peter. 2007. Style and social identities: alternative approaches to linguistic heterogeneity. Berlin: Mouton de Gruyter.

Bürki, YvetTe. 2014. "Dime cómo hablas y te diré dónde vives". Percepción lingüística y representaciones geosociales en la ciudad de Lima. Versants 61(3). En prensa.

Caravedo, Rocío. 2006. La percepción en la fonética del español. En Consejo Superior de Investigaciones Científicas (eds.). Filología y lingüística: estudios ofrecidos a Antonio Quilis. Vol. 1, pp. 113-128. Madrid: CSIC.

2009. Percepción, espacios mentales y variedades lingüísticas en contacto. Neue Romania 39: 171-195.

2012. Las ciudades como espacios mentales y lingüísticos. Reflexiones sobre la variación diatópica del español. Orillas 1: 1-17.

2013. La valoración como modo de percepción y de significación. En Antonio Narbona (coord.). Conciencia y valoración del habla andaluza, pp. 45-71. Sevilla: Universidad Nacional de Andalucía.

Ciccolella, Pablo. 1999. Globalización y dualización en la Región Metropolitana de Buenos Aires. Grandes inversiones y restructuración socioterritorial en los años noventa. EURE 25 , sin paginación.

Chang, Charles. 2008. Variation in Palatal Production in Buenos Aires Spanish. En Maurice Westmoreland y Juan A. Thomas (eds.). Selected Proceedings of the 4th Workshop on Spanish Sociolinguistics, pp. 54-83. Somerville: MA, Cascadilla Proceedings Project.

DIEA = Plager, Federico (coord.). 2008. Diccionario integral del español de la Argentina . Buenos Aires: Voz Activa.

Donni de Mirande, NéLIDA. 2000. Sistema fonológico del español en la Argentina. Revista de español vivo 74: 7-24.

Downs, Roger M. y David Stea. 1973. Cognitive Maps and Spatial Behavior: Process and Products. En Roger M. Downs y David Stea (eds.). Image \& Environment. Cognitive Mapping and Spatial Behavior, pp. 8-26. Chicago: Aldine.

1982. Kognitive Karten. Die Welt in unseren Köpfen. New York: Harper \& Row. 1985. Kognitive Karten und Verhalten im Raum. Verfahren und Resultate der kognitiven Kartographie. En Harro Schweizer (ed.). Sprache und Raum. Psychologische und linguistische Aspekte der Aneignung und Verarbeitung von Räumlichkeit, pp. 18-43. Stuttgart: Metzler.

Eckert, Penelope y Jane Rickford. 2001. Style and Sociolinguistic Variation. Cambridge: Cambridge University Press.

ECKert, Penelope. 2000. Linguistic variation as social practice. Oxford: Blackwell.

Farr, Robert y Serge Moscovici (eds.). 1984. Social representations. London: CUP.

Fought, Carmen (ed.). 2004. Sociolinguistic Variation. Critical Reflections. Oxford: University Press.

Frigerio, Alejandro. 2006. "Negros" y "Blancos" en Buenos Aires: Repensando nuestras categorías raciales. Temas de Patrimonio Cultural 16: 77-98.

Gorelik, Adrián. 1993. Der Ort der Zeit. Die Peripherie von Buenos Aires. Daidalos 50: 106-115.

Gould, Peter. 1972. On mental maps. En Paul W. English y Robert C. Mayfield (eds.). Man, space, and environment, pp. 260-282. New York/London/Toronto: Oxford University Press. 
GulLIVER, Frederic P. 1908. Orientation of maps. Journal of Geography 7: 55-59.

Günzel, Stephan (ed.). 2010. Raum. Ein interdisziplinäres Handbuch. Stuttgart: Metzler.

Hall, Stuart. 1997. Representation. Cultural Representations and Signifying Practices. London / California / New Delhi: SAGE Publications.

HANNERZ, Ulf. 1980. Exploring the city. Inquiries towards an urban anthropology. New York: Columbia University Press.

https://archive.org/details/DannyJamesquemandoE1ParquetCabecitasNegras UrbanLegendsAnd [Consulta 03/04/2014].

Irvine, Judith. 2001. 'Style' as distinctiveness: The culture and ideologies of linguistic differentiation. En Penelope Eckert y Jane Rickford (eds.), pp. 21-41.

JACKSON, PAUL Y RoB Kitchin. 1998. Editorial: Applying Cognitive Mapping Research. Journal of Environmental Psychology 18: 219-221.

JAMES, DANNY. 2012. Quemando el parquet: Cabecitas Negras, Urban Legends, and Abjection. The Construction of Regional Identity in an Argentine Working Class Community. SFU/ UBC Latin American Studies Spring Semester Working Paper Series. Indiana University.

JANOSCHKA, Michael. 2002. Die Flucht vor Gewalt? Stereotype und Motivationen beim Andrang auf barrios privados in Buenos Aires. Geographica Helvetica 57 (4): 290-299.

Jodelet, Denise (ed.). 1989. Les représentations sociales. París: PUF.

JoDELET, DenISE. 1982. Les representations socio-spatiales de la ville. En Pierre-Henri Derycke (ed). Conceptions de l'espace, pp. 145-177. Nanterre: Recherches pluridisciplinaires de 1 'Universite Paris X.

Johnstone, Barbara. 2004. Place, Globalization and Linguistic Variation. En Carmen Fought (ed.), pp. 65-83.

KeEling, David. 1996. Buenos Aires: Global Dreams, Local Crises. Chichester: John Wiley \& Sons.

Kitchin, Robert. 1994. Cognitive maps: what are they and why study them?, Journal of environmental psychology 14: pp. 1-19

Krefeld, Thomas y Elissa Pustka (eds.). 2010. Perzeptive Varietätenlinguistik. Frankfurt a.M., etc.: Peter Lang.

Lefebvre, Henri. [1974] 2000. La production de l'espace. Paris: Anthropos.

Long Daniel y Dennis Preston (eds.). 1999-2002. Handbook of perceptual dialectology. 2 vols. Amsterdam: John Benjamins.

LuCZaK, Urs. 2010. Ambivalenz der Ausgrenzung. Der Lebensort Villa Itati in Buenos Aires als Ressource gesellschaftlicher Teilhabe. Perspektive einer integrativen Planung. Chemnitz: Fakultät für Human- und Sozialwissenschaften.

Lynch, Kevin. 1960. The image of the city. Cambridge: M.I.T. Press.

Mac Giolla Chríost, Diormait. 2007. Language and the city. Basingstoke: Palgrave Macmillan.

Milgram, Stanley y Denise Jodelet. 1976. Psychological maps of Paris. En Harold M. Proshansky, William H. Ittelson y Leanne G. Rivlin (eds.). Environmental psychology: people and their physical settings, pp. 104-124. New York: Holt Rinehart and Winston.

Milgram, Stanley. 1984. Cities as social representations. En Robert Farr y Serge Moscovici (eds.), pp. 289-309. London: CUP.

Milroy, Lesley. 1987. Language and social networks. New York: Blackwell.

2004. Language ideologies and linguistic change. En Carmen Fought (ed.), pp. 161-177.

Paz, Octavio. 2011. México: ciudad del fuego y del agua. La Gaceta 483: 8-12.

Ploog, Katja. 2009. ¿En qué puede contribuir la sociología urbana a la lingüística? Hacia un modelo de las dinámicas lingüísticas aplicado al contexto urbano. Neue Romania 39: 267-286. 
Preston, Dennis. 1989. Perceptual dialectology. Dordrecht NL: Foris.

2010. Language, people, salience, space: perceptual dialectology and language regard. Dialectologia 5: 87-131.

Proshansky, Harold, M. 1978. The city and self-identity. Environment and Behavior 10: 147-169.

Pümpel-Mader, Maria. 2010. Personenstereotype. Heidelberg: Universitätsverlag Winter.

Reguillo, Rossana. 1998. Imaginarios globales, miedos locales. La construcción social del miedo en la ciudad. Ponencia presentada en el IV Encuentro de la Asociación Latinoamericana de Investigadores de la Comunicación. ALAIC. Recife: Universidad Católica de Pernambuco.

Riaño, Yvonne. 2013. Qualitative Methoden in der Geographie. Übungen FS 2013. Gruppe Kulturgeographie, Geographisches Institut der Universität Bern. Skript \& Reader. Disponible en: https://www.academia.edu/5105991/Qualitative_Methoden_in_der_ Geographie [Consulta 01/04/2014].

2014. Einführung Qualitative Methoden für Bild- und Sprachanalysen. Methodenworkshop am Institute of Advanced Study in the Humanities and the Social Sciences (IASH), Universität Bern. Skript \& Reader.

Rose, Gillian. 2012. Visual methodologies. An introduction to researching with visual materials. Los Angeles/London/New Delhi/Singapore/Washington DC: SAGE.

Teruggi, Mario. 1979. Panorama del lunfardo: génesis y esencia de las hablas coloquiales urbanas. Buenos Aires: Sudamericana.

Tolman, Edward. 1948. Cognitive maps in rat and men. Psychological Review 55: 189-208.

Torres, Horacio A. 2001. Cambios socioterritoriales en Buenos Aires durante la década de 1990. EURE 80: 33-56.

Trowbridge, Charles C. 1913. On fundamental methods of orientation and imaginary maps. Science 39: 888-897.

Valera, Sergi y EnRIC Pol. 1994. El concepto de identidad social urbana: una aproximación entre la psicología social y la psicología ambiental. Anuario de Psicología 62: 5-24.

Valera, Sergi. 1996. Análisis de los aspectos simbólicos del espacio urbano. Perspectivas desde la Psicología Ambiental. Revista de Psicología 18: 63 - 84.

1997. Estudio de la relación entre el espacio simbólico urbano y los procesos de identidad social. Revista de Psicología Social 12: 17-30.

Würth, Melanie. 2009. La Ciudad como área lingüistica. Variación y actitudes lingüisticas en la Región Metropolitana de Buenos Aires. Tesina de licenciatura no publicada en el Instituto de Iberorromanística de la Universidad de Basilea.

2013. "Me convertí en una freak del [foto $\square$ op]". Percepción y actitudes acerca de las realizaciones sordas y sonoras de la palatal rehilada en el español porteño. En Cristina Albizu, Hans-Jörg Döhla, Lorenzo Filipponio, Marie-Florence Sguaitamatti, Harald Völker, Vera Ziswiler, Reto Zöllner (eds.). Variante et Variété - Variante e Varietà - Variante y Variedad - Variante und Varietät. Actes du VI Dies Romanicus Turicensis, Zürich, 24-25 de junio de 2011, pp. 87-100. Pisa: Edizioni ETS.

Páginas web:

http://www.atlasdebuenosaires.gov.ar/aaba/index.php?option=com_content\&task=view\&id $=347 \&$ Itemid $=188 \&$ lang $=$ es

http://www.barrio-norte.com/mapa.html

http://www.barriolascanitas.com.ar

http://www.buenos-aires-argentina.info/barrio-norte.html 
http://www.buenosaires.gob.ar/areas/barrios/buscador/ficha.php?id=28 [2/4/14]

http://www.buenosaires.gob.ar/laciudad/ciudad

http://www.clubdetango.com.ar/lunfardeando/shusheta.htm

http://www.frikipedia.es/friki/Cheto_(tribu_urbana)

http://www.frikipedia.es/friki/Negro_cabeza [5/4/14]

http://www.frikipedia.es/friki/Villero

http://www.mauriciomacri.com.ar/

https://pro.com.ar/

http://www.todotango.com/spanish/biblioteca/lexicon/s.asp

$\mathrm{http}: / /$ www.youtube.com/watch?v=_C2RL0SFwG8

http://www.youtube.com/watch? $\mathrm{v}=\overline{\mathrm{itFB}}$ 1Ulviu4

www.youtube.com/user/petercapusottotv 